the tube. By watching carefully the tip of the instrument as it enters the field of vision of the 'scope it can be directed as easily and gently as if it were being passed into a crypt of the tonsil under direct guidance of the eye. After it has entered the lumen of the tube it is under the direction of the sense of touch, but even then it is of importance to watch the tip of the catheter and see that it is kept in contact with the orifice of tube and that no undue force is brought upon it.

In regard to the best drugs for use in the treatment of inflammation of the Eustachian tube, our experience is too limited to say anything at all positively, but of those we have used we have found that a 15 to $20 \%$ of argyrol has given the best results, not only in the acute, but also in the chronic cases.

I do not believe that by this treatment we shall be able to relieve all cases of tubal inflammation, nor will it be likely that all chronic middle-ear diseases whether producing vertigo or not will subside when the tube has been restored to its normal functions, but what we can do is to examine and treat all cases under the guidance of the eye.

This is a great step forward and I believe we shall all achieve results which were impossible under previous methods.

\section{A CASE OF NERVE DEAFNESS DUE TO THE TOXEMIA OF DIABETES.}

BY WM. H. MERRILL, M.D., LAWRENCE, MAss.

As the patient whose case will be reported tonight still has a use for his temporal bones, it would have been well for me to have asked our secretary to place an interrogation point after the title of this report.

An attempt will be made to convey as accurately as possible by words the symptomatology, but at best these will be unsatisfactory data from which to ask the members to agree or disagree with the diagnosis.

When first the diagnosis of a toxic neutritis was made, the writer had a feeling of disgust in having a patient under observation for eight weeks with obscure aural symptoms and not having made a diagnosis which seemed so easy after an urinary analysis had been done.

A later examination of such textbooks and journals as were accessible failing to reveal any mention of diabetes as a cause of auditory neuritis was something of a comfort. A number of writers mention a paralysis of the seventh nerve due to neuritis as an occasional complication of diabetes. The close proximity of the origin and preliminary course of the seventh and eighth nerves would suggest the possibility of a simultaneous involvement, but no facial paralysis was noted in the case of J. B., who was referred to me June 17, 1910.

Family history meager and negative.

Personal history of smallpox and scarlet fever before age of twelve. No pain or discharge from ears is remembered.

Present condition, male, age fifty-five, weight 160, attendant at a county institution. No general symptoms of sufficient importance to attract attention pf the physician who referred him. Deaf in right ear twenty years; does not remember manner of onset, but thinks there has been no tinnitus. He was not aware of any deafness in left ear until morning of June 2, when was so deaf when awakened by member of family that only a shout could be heard.

There was no dizziness or nausea. A little dizziness on stooping had been noticed for a month previous to the attack. This is not present now. Patient was treated by Pollitzer inflation for a week or two by a general practitioner and a little improvement in hearing was noted during this time.

Both membranæ tympani moderately retracted and lacking somewhat in luster. The right has small area of calcareous degeneration. Both ears are readily inflated with catheter but without improvement in hearing.

Hearing test as follows:

\begin{tabular}{lll} 
& \multicolumn{1}{c}{ Right. } & \multicolumn{1}{c}{ Left. } \\
Watch, & O. & C. less distinct on mastoid. \\
Voice, & Shout at 1 $1 \mathrm{ft}$. & $5-40$ (loud voice). \\
A. C., & 512 not heard. ? & 10. \\
B. C., & Not heard. & 5. \\
Lower, & $512 . ?$ & 256. \\
Upper, & 1. & 1.
\end{tabular}

.4 is normal on my Galton whistle. Rotation tests and hot water in left ear applied March 23, 1911, showed normal nystagmus.

Hearing tests were made at intervals of eight or ten days, which showed little change on the whole from the above, but it was noted that the perception varied much at different periods of the same setting. This variability being one of the symptoms mentioned by authors as denoting hysteria, a search was made for some stigmata or history of this disease with negative results.

About a month after coming under observation Dr. Amadon saw Mr. B. and cleaned out the fossæ of Rosenmüller.

July 20 an analysis of urine was made which disclosed a spg. of 1,035 and a large quantity of sugar, no albumin, quantity 4,009. At this time the patient would not admit to having symptoms of any illness. Treatment of ears was discontinued and. he passed into the care of his family physician. When seen a month later there had been a loss of $10 \mathrm{lbs}$. of flesh and there was not the same appearance of good health.

On March 20 a part of the lost flesh had been regained. The hearing tests showed little change from the first one.

The loss of lower tones and the appearance of the membranæ tympani certainly indicates middle-ear deafness, to which I believe a nerve lesion to have been added.

Lack of vestibular symptoms point to involvement of the trunk of the nerve.

Probably it will be willingly agreed that the acetonurea of diabetes, in common with the toxemia of syphilis, influenza, malaria, etc., could easily produce a neuritis of the eighth nerve as of others which are rather frequently involved. The only lesson of importance the writer sees in this, perhaps rare case, is the necessity of always bearing in mind that grave systemic diseases often have their first manifestations in the organs of special sense, and we should be alert to recognize them. Patients frequently consult the oculist or aurist without visiting their family physician, or if they do ask advice of their physician, they 
present slight or no symptoms of a beginning systemic disease which attracts attention.

The only reports in literature I have found were references furnished me by Dr. Shambaugh, and are as follows: Hegher, Zeitschrift für Ohrenheilkunds, vol, lv, page 111 . An acute neurolabrynthitis which was characterized by the marked labyrinthine symptoms, vertigo, tinnitus and deafness. The patient had $\frac{1}{2}$ of $1 \%$ of sugar in urine, which was eliminated by diet and recovery, but not complete in high times, followed.

Witmach, Zeitschrift, vol. liii, page 19. Autopsy findings in case of ten-year-old girl who died in diabetic coma which showed degenerative neuritis and atrophy of eighth nerve.

Witmach also mentions diabetes as a cause of auto-intoxication neuritis, Zeitschrift, vol. xlvi, page 1.

\section{LATERAL DEVIATIONS OF THE EXTERNAL NOSE.}

BY A. COOLIDGE, JR., M.D., BOSTON.

VIEwED from in front, the line of the nose in a typical face is straight and symmetrical. Frequently, however, as a result of trauma or irregular growth, the nasal dorsum deviates either as a whole or in part from the middle line. These lateral deviations of the external nose may be grouped into three main types.

In the first, the whole nose deviates to one side, the dorsum is straight, there is no angle laterally between the upper bony and lower cartilaginous portions, but the tip is on one side of the median line. This type is due, at least for the most part, to asymmetrical growth.

In the second type the bony upper half deviates to one side, while the cartilaginous lower half tends to return to the median line, causing a lateral angle in the dorsum. This deformity is the same as occurs with a fracture or dislocation of the nasal bones, and when not due to recent trauma is generally the result of an old unreduced dislocation.

In the third type the nasal bones are in the middle line, while the cartilaginous portion is bent to one side. This may be developmental or it may be the result of old trauma of the quadrangular cartilage of the septum from a blow on the tip of the nose modified by subsequent eicatrization.

Two or more of these types of variation may be combined.

When the external nose deviates, there is necessarily also more or less deviation of the nasal septum. In traumatic cases the septum is bent as a result of the external violence. When the asymmetry is due to irregular growth, the deviation of the septum may be the primary cause of the external deviation. With the forward growth of the septum in àdolescence it frequently becomes deviated or bent, and the external nose, bony as well as cartilaginous, follows the lead of the septum and adapts itself to the asymmetrical cavities within. This applies not only to the nasal bones, but also to the nasal processes of the superior maxilla, which, as they are joined to the whole lateral edge of the nasal bones, are practically one piece with them.

As a disfigurement, a lateral angle between the bone and the cartilage is of more importance than a deviation of the nose as a whole from the median line. For this reason, there is seldom any reason for correcting a deviation of the first type. Often a considerable degree of lateral displacement is not noticed if the line of the dorsum is straight.

In the second type, where the nasal bones deviate, and the lower half of the nose returns towards the median line, the problem is somewhat similar to the reduction of a recent dislocation, except that the bones must be broken or cut. The distance from the dorsum of the nose to the level of the cheek, that is, the combined breadth of the nasal bones and nasal process, is the same on the two sides if the nose is in the middle line, but different if it deviates to one side. In other words, in order to replace the dorsum into the middle line it is necessary to make the distance equal on the two sides. If the narrower side cannot be broadened this must be done by narrowing the broader one, by sliding the edge of one nasal bone under the nasal process. This necessarily somewhat lowers the dorsum, or, in other words, reduces the profile. It may therefore be said that if there is height to spare, the operation is a simple one. It may be done as follows: An incision one-eighth of an inch in length is made along the middle of the junction of the nasal bone and the nasal process on each side. Through this a chisel separates the nasal bones from the nasal processes as high as the neck of the nasal bones. Taking advantage of the mobility of the skin, the chisel is turned at a right angle, and cuts through the neck of the nasal bones. The nasal bones from the neck downwards are then freely movable. Then upon the broad side, the periosteum of the upper edge of the nasal bone and the lower edge of the nasal process is elevated, making a pocket into which the nasal bone is pressed, and held in position by a strap depressing the dorsum. The incisions are closed without sutures, they heal by first intention and leave no appreciable scar. Enough of the septum must be resected either before or at the time of operation to correspond to the reduced height of the dorsum.

A nose which is too high and prominent, but straight, may be reduced in height by the same operation, except that the nasal bones on both sides instead of only one are pushed under the nasal processes. The bones are generally so thin that no line along their point of separation shows through the skin.

For the third type of lateral deviation, when the bones are in the middle line but the cartilage is bent to one side, a resection of the cartilage must be done. As little cartilage as possible should be removed, to save the tip of the nose from sinking. Each case presents its own problems, which are often difficult, and the results may be endangered 